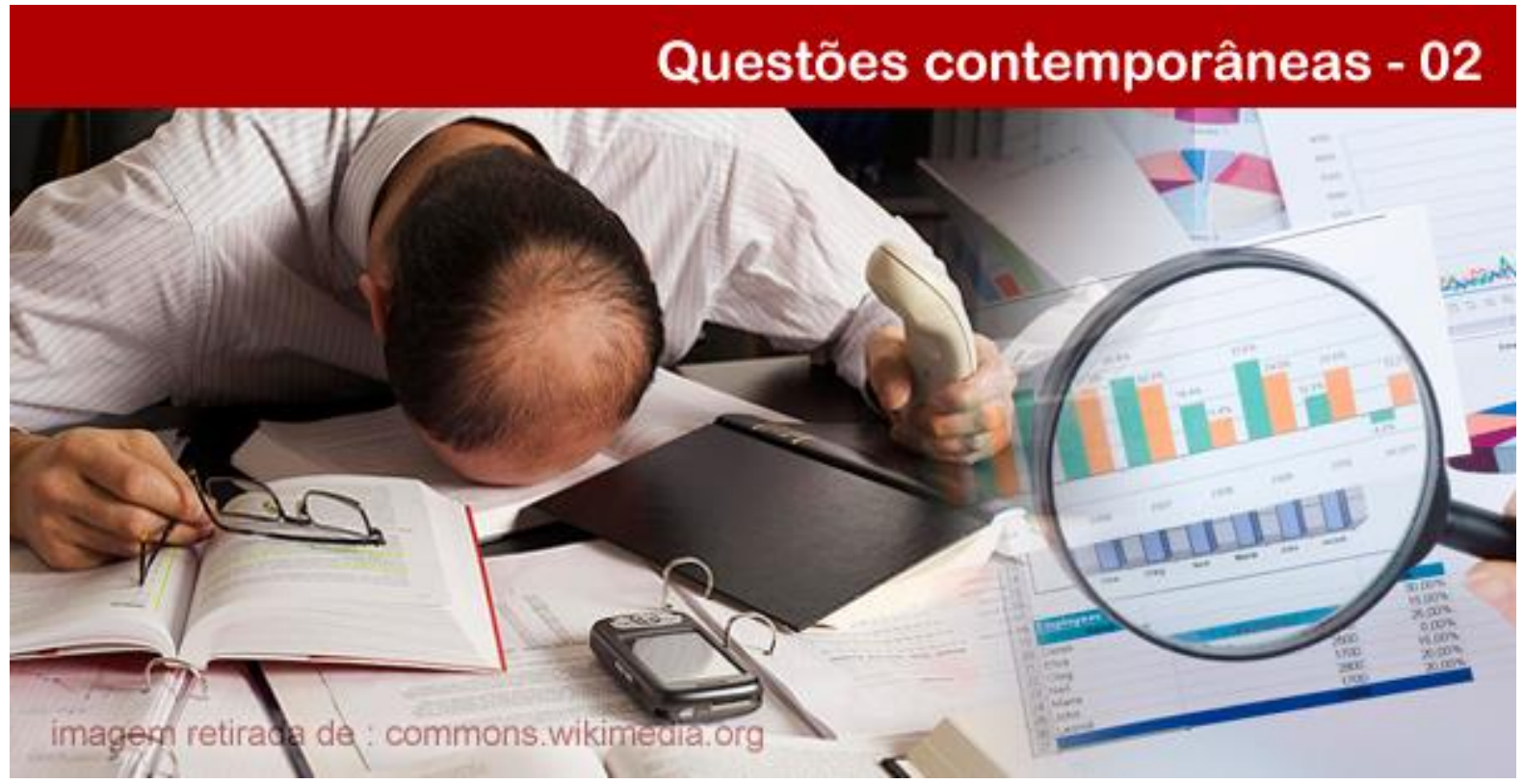

\title{
CAFETINAGEM ACADÊMICA: ALGUÉM TEM MEDO DE PESQUISAR AS RELAÇÕES ACADÊMICAS?
}

Igor Vinicius Lima Valentim

Professor da Faculdade de Educação da Universidade Federal do Rio de Janeiro e membro do CSG, SOCIUS, ISEG da Universidade de Lisboa.E-mail: valentim@gmail.com.

Resumo: Conhecimentos constituem apenas uma parcela dentre as inúmeras construções ocorridas na Academia. As universidades são ótimas para analisar os outros, mas investigam pouco a respeito de si mesmas. Ainda que ocorram diversas produções no cotidiano acadêmico, é raro encontrar pesquisas nas quais o próprio fazer e as relações acadêmicas são analisados criticamente. Que subjetividades são construídas nas relações acadêmicas? Por meio de uma autoetnografia, é utilizado o parecer recebido após a submissão de um projeto de pesquisa a um edital de uma universidade brasileira para problematizar suas implicações no que se relaciona à construção de subjetividades, a fim de responder a seguinte questão: em que medida participamos de diferentes modalidades de cafetinagem acadêmica?

Palavras-chave: Universidade. Relações acadêmicas. Educação Superior. Autoetnografia. Subjetividade.

\section{ACADEMIC PIMPING: IS ANYONE AFRAID OF RESEARCHING ACADEMIC RELATIONSHIPS?}

Abstract: Knowledge amount to just a small part of the numerous things that are produced in the Academe. Universities are great to analyse others but investigate very little about themselves. Although several things are produced in Academe's daily routines, it is rare to find research in which academic relations and modus operandi are critically analysed. What subjectivities are produced in academic relations? By means of an autoethnography I use the review I received after submitting a research project to a Brazilian university call in order to problematize this review's implications in relation to subjectivies' construction: to what extent do we participate in different types of academic pimping?

Keywords: University. Academic relations. Higher Education. Autoethnography. Subjectivity.

\section{Universidades, subjetividades e relações acadêmicas}

Em uma lógica capitalista centrada na produção de comportamentos e que busca fazer com que determinados valores sejam aprendidos, vividos e sentidos como naturais, Guattari e

\section{POLÊM!CA $\mid$ LABORE (}

Polêmica - Revista Eletrônica da Uerj - Rua São Francisco Xavier, 524, $1^{\circ}$ andar bloco D, sl.1001 • Tels.: +55 21 2334-4088 / 4087 • http://www.e-publicacoes.uerj.br/index.php/polemica/index http://www.labore.uerj.br • laboreuerj@yahoo.com.br 
Rolnik (2007, p. 33) apontam para a centralidade da subjetividade: uma subjetividade de natureza 'maquínica', “fabricada, modelada, recebida, consumida”. É importante refletir a respeito das maneiras por meio das quais esses modos ou estilos de existir e viver são produzidos.

$\mathrm{Na} / \mathrm{com}$ a Academia são (re)produzidos valores, modos de pensar, sentir, lidar com os outros e enxergar a si: subjetividades, aqui entendidas como as maneiras pelas quais os sujeitos fazem experiência de si (FOUCAULT, 1999). "A produção dos modos de existência ou estilos de vida" é justamente o que Deleuze (1992, p. 142) chama de subjetivação. Existem diversas 'máquinas' produtoras de subjetividade, tais como empresas e a mídia, para citar apenas dois exemplos. E as universidades são parte cada vez mais importante no que se refere aos processos de subjetivação.

Conhecimentos - científicos ou não - constituem apenas uma parcela dentre as inúmeras construções ocorridas nas universidades. Dentre os teóricos clássicos, Weber (1989) destaca dilemas da ocupação científica universitária: o cientista faz parte da "fábrica da ciência", e a paixão e os temperamentos dos professores podem influenciar acadêmicos iniciantes. Já Pierre Bourdieu $(1984 ; 2004)$ argumenta que o campo científico é constituído por forças que visam à conservação ou transformação do status quo.

A maior parte dos cursos universitários prepara, com suas especificidades e particularidades, cada vez mais profissionais voltados para sonhar em triunfar em um 'mercado' individualista e selvagem que prega valores criadores e aprofundadores da miséria, da competição e de injustiças sociais. Se hoje "é fundamentalmente das forças subjetivas, especialmente as de conhecimento e criação", que o regime capitalista se alimenta (ROLNIK, 2006a, p. 13-14), parecem restar poucas dúvidas sobre a importância do papel que os cursos universitários podem ter nas sociedades contemporâneas.

Enquanto alguns valores se expandem e se naturalizam para todas as áreas da vida humana, é importante refletir em que medida eles podem ser estimulados nas próprias relações estabelecidas entre/para com acadêmicos. Uberti (2006, p. 110) sugere que é preciso pensar "a que problemas a educação respondeu, historicamente, e a que problemas necessita responder agora", sendo tarefa de todos lutar por um mundo mais justo e humano.

Nas relações acadêmicas, o corpo, o espírito e a mente de todos são objetos de experiências (FERREIRA, 1996). É possível considerar, portanto, que a pedagogia, enquanto ciência da educação, está implicada na fabricação de seres humanos por exercer poderes e

\section{POLÊM!CA $\mid$ LABORE}


forças que excluem, impedem, limitam, proíbem, impõem, incitam, induzem, estimulam e favorecem as possibilidades de os indivíduos serem de um modo ou de outro e de agirem em uma ou outra direção (FOUCAULT, 1995; GARCIA, 2001; 2002). Que subjetividades são construídas nas relações acadêmicas? Que valores são estimulados e naturalizados nestas/por estas relações? Embora as perguntas sejam pertinentes, não é exagero algum afirmar que a Academia é habilidosa em analisar entes externos, mas ainda investiga pouco a respeito de si própria, de seus modos de funcionamentos, relações, bastidores, silêncios e não-ditos.

Latour e Woolgar (1982) investigaram as práticas de um instituto de pesquisa, mas parece raro encontrar investigações em que as relações acadêmicas estejam no centro das análises. Pierre Bourdieu escreveu seu clássico Homo Academicus (1984), dedicado à temática do mundo acadêmico, mas a obra pode ser até mesmo considerada marginal dentro da coletânea do autor francês. É importante a afirmação do professor brasileiro - radicado nos Estados Unidos da América (EUA) - Marcelo Diversi, quando diz que vê seus novos campos de batalha no trabalho acadêmico justamente "como a sala de aula universitária e os tradicionais locais onde a produção de conhecimento ocorre, como periódicos, livros e conferências acadêmicas" (DIVERSI e MOREIRA, 2009, p. 208).

Em livro sobre sua vida, Laurel Richardson (1997, p. 53) já afirmou que o "trabalho intelectual é feito em instituições sociais e por meio de relações sociais particulares". A partir de um entendimento das relações acadêmicas construídas como processos de subjetivação, busco neste texto inverter o olhar tradicional e colocar a Academia e o fazer acadêmico como focos de investigação.

O foco de análise deste artigo está ligado a uma estória vivenciada por mim em uma universidade pública brasileira (UNIV) - a qual opto por preservar o nome, tendo em vista que isto em nada altera os propósitos político-pedagógicos do texto e não desejo expor ou magoar outras pessoas que, por ventura, pudessem se sentir atingidas.

Enquanto eu lecionava na instituição, submeti um projeto de pesquisa focado justamente no tema das relações acadêmicas a um edital institucional de bolsas de iniciação científica no âmbito da Pró-Reitoria de Pesquisa da citada universidade (PROPG/UNIV).

Escrevo este texto com o intuito de problematizar as relações acadêmicas e as subjetividades que elas constroem, ou seja, para questionar e refletir a respeito dos estímulos e impactos que um parecer como o recebido pode levar às subjetividades construídas na/com a Academia. Ciente da necessária delimitação, com o auxílio do método autoetnográfico,

\section{POLÊM!CA $\mid$ LABORE}


construo neste trabalho uma análise do parecer que recebi após a submissão do referido projeto, entendendo-o como espaço/lócus de relações acadêmicas.

Concordo com Larrosa (2009, p. 8) quando ele afirma que um dos maiores perigos para a pedagogia de hoje "está na arrogância dos que sabem, na soberba dos proprietários de certezas" e que "agora o urgente é recolocar as perguntas, reencontrar as dúvidas e mobilizar as inquietudes".

O texto dialoga com referenciais como Foucault, Deleuze, Guattari e Rolnik e, portanto, não apresenta certezas nem pretensões universalizantes. Não apresento aqui verdades definitivas, situações generalizáveis ou panoramas estatisticamente válidos e reproduzíveis. Assim como também não esgoto aqui (e nem me proponho a isso) todas as possibilidades e perspectivas de análise das relações acadêmicas. Como mencionado, este artigo busca problematizar as relações acadêmicas e as subjetividades por elas produzidas.

Lembro-me das palavras de Clareto e Oliveira (2010, p. 65) quando afirmam que "escrever é com o corpo" e problematizar o mundo. Para atingir os objetivos propostos com este texto e supra explicitados, construo aqui uma narrativa autoetnográfica.

\section{Uma autoetnografia na universidade}

A autoetnografia tem a ver com estórias e histórias. Com narrativas. Uma de suas principais características é que ela busca superar alguns componentes da etnografia tais como a separação entre o observador e o observado, a suposta neutralidade, descrições neutras de objetos déjà-là e o desprendimento.

É importante ressaltar que as narrativas autoetnográficas não têm o objetivo de contar estórias da forma com que aconteceram, nem o de buscar representar um passado estático e sequencial, linear, acessível por meio da memória. Por isso, neste texto autoetnográfico que aqui construo, não há preocupação com a suposta veracidade ou facticidade da narrativa, mas com sua credibilidade, a qual está ligada a questões como coesão da estória e os sentidos construídos a partir dela. Para Laurel Richardson (1997, p. 77), "a credibilidade é conseguida pela seleção dos detalhes, tom, imagens, metáforas e, em parte, por meio de localizar as estórias em um contexto mais amplo".

No sentido do exposto no parágrafo anterior, mas sem lidar especificamente com autoetnografias, Veiga-Neto e Lopes (2010) consideram que em estudos ligados ao campo Foucaultiano, não há lugar para uma pergunta como 'isso é verdadeiro?', mas sim para outras,

\section{POLÊM!CA $\mid$ LABORE}


como por exemplo: “'de que maneira isso tornou-se verdadeiro?', 'que efeitos essa verdade produz?', 'quais nossas relações com essa verdade?' e/ou 'como poderemos alterar essa verdade?"” (p. 35).

Um texto com inspiração autoetnográfica pode ter como intuito estimular a reflexão a respeito de perguntas tais como: "o que as experiências dos autores sugerem a respeito da cultura?", não esquecendo que "toda estória que construímos é parcial, privilegiada e retoricamente construída para um público" (ADAMS, HOLMAN JONES e ELLIS, 2015, p. $82)$.

Daniela Versiani é uma das poucas brasileiras a investigarem a respeito da autoetnografia como método. Para ilustrar como este método é pouco disseminado em termos nacionais, uma busca com o termo 'autoetnografia' realizada, a título de exemplo, na base de textos do periódico Educação \& Realidade, em fevereiro de 2016, não encontrou nenhum artigo com o termo, nem no título, nem no resumo, nem no texto completo.

De acordo com Versiani (2005, p. 101), o conceito da autoetnografia foi criado/construído para tentar dar conta "do reconhecimento da subjetividade como fator importante no processo de construção de conhecimento". Nesta linha de pensamento, a autora considera ainda que podemos pensar em autoetnografias como "espaços comunicativos e discursivos através dos quais ocorre o 'encontro de subjetividades', a interação de subjetividades em diálogo" (idem, p. 87).

Autoetnografias são construídas com pensamentos, sentimentos, sensações e experiências que nos trazem dúvidas e incertezas "e que nos fazem questionar, reconsiderar e reordenar nossos entendimentos de nós próprios, de outros e de nossos mundos" (ADAMS, HOLMAN JONES e ELLIS, 2015, p. 47). Ou seja, podem estar relacionadas à desterritorialização (ROLNIK, 2006a) e ao desassossego.

Para Tony Adams, a "autoetnografia é um método que nos permite reconsiderar como nós pensamos, como nós pesquisamos e mantemos relações e como nós vivemos" (ADAMS, HOLMAN JONES e ELLIS, 2015, p. 8). Já Versiani (2005, p. 218) enxerga neste método um "potencial para alterar nossos modos de percepção dos processos de construção de subjetividades, culturas e produção de conhecimento". Para esta última autora, a autoetnografia pode permitir essas mudanças principalmente devido ao modo contínuo por meio do qual se desenrola a escrita das narrativas autoetnográficas: “ela acontece. É partícipe

\section{POLÊM!CA $\mid$ LABORE}


da realidade. Extensão da vida e do movimento que há no que está vivo" (VERSIANI, 2005, p. 224-225).

Escrever de acordo com esses princípios tem também a ver com os pensamentos do espanhol Jorge Larrosa (2015, p. 40) quando ele afirma que "ler e escrever (escutar e falar) é colocar-se em movimento, é sair sempre para além de si mesmo, é manter sempre aberta a interrogação acerca do que se é”.

Os autoetnógrafos, como são chamados aqueles que utilizam o método, usam suas experiências para criarem "versões complexas, nuançadas e compreensivas de normas culturais, experiências e práticas" (ADAMS, HOLMAN JONES e ELLIS, 2015, p. 33), bem como para refletir a respeito do caráter ético, estético e político presente nessas dimensões: precisamos usar as estórias que contamos para quebrar silêncios há muito instaurados a respeito de poder, relações e tabus culturais (idem, p. 103).

A autoetnografia é um método que se propõe a construir conhecimentos sobre vidas, experiências, relações, e não informações gerais a respeito de grandes grupos de pessoas (ADAMS, HOLMAN JONES e ELLIS, 2015, p. 21). A autoetnografia está relacionada a nossas marcas, cicatrizes, ao que vivemos, sentimos na pele, na mente, no corpo, na alma. Tem a ver com o que nos marca e não necessariamente com aquilo que marca.

Como um autoetnógrafo, conto neste texto "uma estória situada, construída da minha posição atual, uma estória que é sempre parcial, incompleta e cheia de silêncios, escrita em um tempo particular, para um propósito particular e um público particular" (ELLIS, 2009, p. 13).

\section{O projeto submetido e o parecer recebido}

Como já mencionei brevemente neste texto, o principal objetivo do projeto de pesquisa que eu submeti à $\mathrm{PROPG/UNIV} \mathrm{era} \mathrm{analisar} \mathrm{criticamente} \mathrm{a} \mathrm{própria} \mathrm{universidade} \mathrm{e} \mathrm{as}$ relações construídas entre seus integrantes. Mais especificamente, o projeto tinha como proposta principal um recorte dedicado ao curso de graduação em Administração da instituição, buscando refletir/construir, junto com estudantes, professores e técnicos, olhares e sentidos a respeito do fazer acadêmico, das relações acadêmicas e das subjetividades construídas na/com a universidade. Embora pudesse ser realizado em qualquer curso da UNIV, devido ao seu escopo ainda inicial, propus começar as atividades pelo curso de

\section{POLÊM!CA $\mid$ LABORE}


graduação em Administração devido ao fato de ser aquele ao qual eu estava vinculado à época.

O projeto possuía, em linhas gerais, um referencial semelhante ao deste artigo, ou seja, partia da ideia de que na Academia são construídas formas de se relacionar entre todos os envolvidos, profissionais acadêmicos ou não. São produzidos e reproduzidos valores norteadores de convivências, para além de modos de ver, sentir e estar no mundo, modos de trabalhar, falar e interagir, modos de lidar com os outros e de enxergar a si próprio: processos de subjetivação. Neste sentido, o projeto de investigação perguntava: Em que bases acontecem essas relações entre profissionais acadêmicos, alunos e técnicos administrativos? Que valores estimulam? O que produzem?

Para atingir os objetivos propostos, a investigação propunha adotar métodos no sentido de convocar integrantes da Academia a analisar criticamente como as relações entre alunos, professores e técnicos administrativos eram construídas, bem como que valores, modos de ser, viver e sentir eram produzidos e reproduzidos nas convivências desenvolvidas.

Eu cumpria todos os requisitos "burocráticos" para participar do edital institucional de bolsas de iniciação científica da UNIV, tais como ter o título de doutor, algumas publicações nos últimos cinco anos e já ter orientado bolsistas de extensão, monitoria ou iniciação científica. Cada docente poderia solicitar uma bolsa, com duração máxima de doze meses, para algum aluno que tivesse interesse em desenvolver o projeto de maneira conjunta. Como eu já tinha um estudante trabalhando comigo de maneira voluntária no âmbito deste mesmo projeto, isto é, sem remuneração, decidi submeter o projeto ao edital da PROPG/UNIV.

Após cerca de um mês e meio de espera, recebi por parte da instituição a notícia de que as avaliações estavam disponíveis na plataforma eletrônica da PROPG/UNIV. Ao entrar no sistema com meu login e senha, e buscar o resultado e os pareceres avaliativos, constatei que o projeto havia recebido 34 pontos em 60 possíveis, alcançando 56\% em uma escala percentual. Tendo em vista que para a concessão de uma bolsa de iniciação científica dentro do edital ele deveria obter pontuação de pelo menos $60 \%$, a partir da pontuação recebida o projeto não foi contemplado.

“Apenas um ponto! Se eu tivesse conseguido 35 pontos, chegaria aos $60 \%$ necessários!"”.

\footnotetext{
${ }^{1}$ Em consonância com o método autoetnográfico utilizado neste artigo, são incluídas diversas falas, questionamentos e diálogos do autor.
}

\section{POLÊM!CA $\mid$ LABORE}


Fiquei curioso para ler os pareceres avaliativos e entender as razões pelas quais o projeto teve uma bolsa negada por apenas um ponto. Minha surpresa veio quando percebi que não haviam pareceres, no plural: o projeto havia sido analisado por apenas um(a) parecerista.

Para os propósitos deste texto, mais interessante do que discutir a matemática da não concessão por apenas um ponto e a magia dos números e estatística, parece ser justamente analisar o parecer qualitativo recebido, reproduzido a seguir, no qual o(a) avaliador(a) anônimo(a) explica os motivos para a não concessão da bolsa:

\begin{abstract}
A pesquisa proposta só seria relevante se contemplasse outras universidades. O próprio desenvolvimento intramuros já aponta uma fragilidade, possíveis constrangimentos e uma visão muito limitada e circunstancial. Dificilmente a metodologia, conforme explicitada, dará conta de chegar a uma análise isenta e imparcial. Ainda, faltam referenciais teóricos importantes para o tema proposto, como Durkheim, Weber e Bourdieu, entre outros. O parecer não é favorável ao projeto.
\end{abstract}

Choque. Surpresa. Frustração.

"Como assim? É isso mesmo que está escrito? Negaram o projeto alegando esses motivos?".

A afirmação de que "a pesquisa proposta só seria relevante se contemplasse outras universidades" (grifo meu) de imediato trouxe choque e perplexidade. Por um lado, parece inegável que quanto maior o número de espaços de um projeto que busque investigar e analisar as relações acadêmicas, mais rica pode ficar a pesquisa. Entretanto, este não era um projeto comparativo nem tampouco apoiado na ideia de representação, muito pelo contrário.

"Será que o(a) parecerista realmente leu o projeto? O referencial teórico que serve de base a ele?".

Pelo menos dois pontos merecem reflexão.

Em primeiro lugar, tendo em vista que o tema central do projeto de pesquisa submetido - relações acadêmicas - se apresenta ainda hoje em grande medida ausente e pouquíssimo pesquisado na Academia brasileira, é difícil compreender a consideração de que uma pesquisa como a proposta só teria relevância se fossem contempladas outras universidades. Não é que estivesse presente no parecer uma sugestão de expansão do projeto em nome de uma investigação mais completa. Não! É uma negativa em realizá-lo no contexto local da UNIV, na qual ainda não era realizada nenhuma investigação dedicada a essa

\title{
POLÊM!CA $\mid$ LABORE
}


temática, usando-se como justificativa que apenas outros locais de investigação podem trazer relevância.

\begin{abstract}
Escuto muitas vozes elogiarem meu trabalho, mas nunca encontrei nenhum acadêmico iniciante fazendo isso. As pessoas podem gostar da sua prosa, mas não vão te contratar. Você tem que ser flexível para ser um acadêmico. Não deixe a raiva levar o melhor de você. É legal, mas por que você faz isso aqui na Academia? [...] Existem mais vozes, mas estou cansado. O que é isso? Não tenho condições de ter um emprego porque não me comporto, e não penso, não pergunto/respondo, e não escrevo/pesquiso/desenvolvo as mesmas perguntas que os outros? (DIVERSI, MOREIRA, 2009, p. 168).
\end{abstract}

Em segundo lugar, o parecer e seu/sua autor(a), ao enxergar validade e relevância apenas quando uma investigação está ligada à quantidade, números e significância estatística, marcam uma visão de mundo bem definida e defendida por muitos, inclusive com fortes influências desde o projeto Iluminista, mas que não é única. É justamente sentindo as singularidades de cada contexto, de cada local, que a pesquisa vai se construindo e se enriquecendo.

Jorge Larrosa (2009, p. 9), inspirado em Nietzsche, afirma que "não há um eu real e escondido a ser descoberto. Atrás de um véu, há sempre outro véu; atrás de uma máscara, outra máscara; atrás de uma pele, outra pele”. Aí reside a importância da criação, da invenção. Não há uma essência a ser buscada. Nem identidades estáveis, estanques, imutáveis.

Não tenho o objetivo de realizar pesquisas homogeneizantes. Não estou em busca de verdades definitivas ou generalizáveis. As verdades aqui são entendidas como circunstanciais e não como perenes ou imutáveis (BARROS, 2008, p. 75). Busco dar atenção àquilo que me atravessa, às singularidades, afetos, subjetividades. Enquanto escrevo e reflito sobre o parecer recebido, penso no texto de Larrosa no qual ele afirma crer

que para além ou para aquém de saberes disciplinados, de métodos disciplináveis, de recomendações úteis ou de respostas seguras; para além até mesmo de ideias apropriadas e apropriáveis, talvez seja hora de tentar trabalhar no campo pedagógico pensando e escrevendo de uma forma que se pretende indisciplinada, insegura e imprópria. O discurso pedagógico dominante, dividido entre a arrogância dos cientistas e a boa consciência dos moralistas, está nos parecendo impronunciável. As palavras comuns começam a nos parecer sem qualquer sabor ou a nos soar irremediavelmente falsas e vazias. E, cada vez mais, temos a sensação de que temos de apreender de novo a pensar e escrever, ainda que para isso tenhamos de nos separar da segurança dos saberes, dos métodos e das linguagens que já possuímos (e que nos possuem) (LARROSA, 2015, p. 7).

\title{
POLÊM!CA $\mid$ LABORE
}

Polêmica - Revista Eletrônica da Uerj - Rua São Francisco Xavier, 524, $1^{\circ}$ andar 
Não é difícil perceber que apenas uma única universidade, sozinha, já engloba infinitos mundos diferentes. Ao olhar com atenção para o contexto universitário brasileiro, até mesmo um departamento já apresenta farta diversidade no que diz respeito às relações estabelecidas, subjetividades construídas, valores estimulados.

A partir de um parecer como o que recebi, que considera que o número de universidades pesquisadas deva ser o critério responsável pela relevância de uma investigação, diversas pistas podem ser visualizadas a respeito do tipo de ciência que se deseja construir, bem como daquela que é considerada relevante.

Como é possível afirmar que uma investigação só tem relevância se for feita em contextos outros, quando nem sequer os (múltiplos) contextos da própria universidade em que se está alocado foram pesquisados? A relevância de uma pesquisa seria então meramente quantitativa? Estatística? Ou esse é apenas um argumento utilizado para a universidade não investigar a si própria e não analisar suas próprias condutas, relações e valores?

Ao continuar a análise do parecer e me deparar com a consideração de que "o próprio desenvolvimento intramuros já aponta uma fragilidade, possíveis constrangimentos e uma visão muito limitada e circunstancial", pergunto: "Qual o constrangimento que existe ou pode existir em se investigar o que se faz, o que se pratica? Em ser autocrítico? Em estimular a autocrítica? Estaria a universidade construindo em seu cotidiano tantos absurdos ao ponto de ficar constrangida de olhar para si mesma? Uma pesquisa forte é aquela na qual se investigam os outros, sem constrangimento algum, mas frágil quando se olha para si?".

O comentário de que a pesquisa é limitada e circunstancial por investigar apenas a própria universidade da qual o proponente faz parte remete novamente a uma avaliação que considera como sinônimo de validade a estatística, desprezando as verdades entendidas justamente como circunstanciais, provisórias, concepção esta que está na base teórica do projeto ora submetido.

"Será que realmente leram meu projeto? Ou ele só tem mérito se compartilhar dos mesmos princípios e visão de mundo de quem o lê e avalia?".

No mundo acadêmico, supostamente guardião da autonomia e liberdade de pensamento, conhecimento e investigação, fica difícil compreender como um projeto pode ser descartado a partir da visão de mundo de um(a) único(a) avaliador(a).

\section{POLÊM!CA $\mid$ LABORE}


Só é válido o projeto que compartilha da visão de mundo cada vez mais dominante ou, ainda mais grave, da mesma visão de mundo dos avaliadores? Onde está o estímulo à diversidade? À multiplicidade? Aos métodos, visões, paradigmas e bases diferentes?

Para aprender a crer na vossa 'veracidade' necessitava ver-vos romper com a vossa vontade veneradora. Por mim, chamo verídico àquele que vai para os desertos sem Deus, aniquilando o seu coração reverente (NIETZSCHE, 2013, localização 1636).

Não parece mera coincidência que, logo na sequência do parecer recebido, o(a) avaliador(a) expresse que o projeto terá dificuldade, com sua metodologia, em chegar a uma análise isenta e imparcial. Esse tipo de ponderação reforça as considerações já feitas nos parágrafos anteriores e remonta a uma concepção de ciência ligada a verdades absolutas e verificáveis, generalizáveis, atreladas a uma busca pela neutralidade, imparcialidade e isenção, para além da separação entre pesquisador e pesquisado. Esta é uma visão de mundo que alimenta dicotomias como certo e errado, bem e mal, e que está presente desde épocas nas quais um estudo só era considerado científico se estivesse sob o viés das ciências matemáticas, exatas e biológicas, ancoradas nos experimentos e no positivismo. Um paradigma dito da ciência moderna (VEIGA-NETO, 2002), apoiado na razão, na consciência, no sujeito soberano, no progresso e na totalidade do mundo.

O parecer recebido pode indicar, para além do já mencionado, que a própria liberdade/autonomia de pesquisa acadêmica está cada dia mais ameaçada. Ameaçada? Ou será que ela sempre fez mais parte de uma retórica do que das práticas efetivas? É importante refletirmos até que ponto, embora sempre presente nos discursos, a liberdade/autonomia está presente nas práticas e relações acadêmicas.

Não apenas em território brasileiro, mas em nível internacional, as condições materiais de pesquisa e de infraestrutura, apoios e até mesmo bolsas para estudantes, hoje, são alocadas majoritariamente para áreas tais como as ciências da saúde, exatas e engenharias. Se parece inquestionável que existe um privilégio em nível mundial pelas áreas mencionadas em detrimento de outras tais como humanidades, artes e ciências sociais, mesmo dentro dessas áreas 'marginais' existem diversas disputas entre diferentes visões de mundo, dentre as quais algumas dominantes que, infelizmente, nem sempre estimulam multiplicidades. Ou seja, de que autonomia se trata quando determinados valores e visões de mundo são privilegiados em detrimento de outros, inclusive nas avaliações?

\section{POLÊM!CA $\mid$ LABORE}


Ao menos no contexto do edital aqui analisado, com base no parecer recebido, os recursos disponibilizados parecem ser distribuídos preferencialmente entre aqueles que realizam pesquisas que compartilham de uma visão de mundo positivista e supostamente neutra. Mas o que é uma análise neutra e imparcial quando ela é feita por pessoas? Que análise é neutra e imparcial quando é inseparavelmente construída por subjetividades, valores, modos de pensar, ser, agir, ver e trabalhar?

Essa imparcialidade só parece possível para aqueles pesquisadores que internalizam e (re)produzem a crença na neutralidade mencionada e em verdades absolutas e únicas, que utilizam a estatística como indicador de validade, que apostam no controle como garantia de qualidade, que preferem as provas e verificações em detrimento da confiança e da abertura, que consideram as pessoas avaliadas como mais competitivas como verdadeiramente superiores às demais, que criticam mais os outros do que a si mesmos e que, também por isso, preferem constranger os outros do que a si mesmos.

É excelente nessa discussão lembrar da metáfora do 'homem da sanguessuga', construída por Deleuze (2013, p. 43): o homem que "quis substituir os valores divinos, a religião e até a moral, pelo conhecimento", um conhecimento que "deve ser científico, exacto, incisivo". Entretanto, quando isso acontece, é a vida que sofre e é julgada e mutilada.

Lembro-me das palavras de Richardson (1997, p. 208), quando ela afirma que novos discursos ameaçam não apenas a noção de uma ciência puramente objetiva que remete ao século XVII, mas também "o poder (prestígio/salário) daqueles que se entrincheiram dentro da universidade". Para a autora, os mais jovens e inexperientes são os mais vulneráveis nestes jogos.

"Preciso bater continência? É preciso agir como os mestres agem ou esperam?".

\section{Em direção à cafetinagem acadêmica?}

Quais são as implicações de uma Academia baseada em pareceres como o recebido? O que isso implica em termos de atitudes, cotidiano, relações, desejos e subjetividades? O que fazer então após receber o parecer aqui analisado?

"Fiquei pensando... quando o pedido de uma bolsa para remunerar um aluno interessado em participar do projeto de pesquisa é negado, o que fazer? Não pesquisar o tema ligado ao projeto? Buscar um tema mais aceito e reconhecido? Pesquisar sozinho?”.

\section{POLÊM!CA LABORE}


O recado para mim foi claro e implicou que, com esse tema, olhando para a própria universidade, o projeto não seria apoiado pela instituição. Quem quer pesquisar certo tipo de assunto, pode fazê-lo, mas sem apoio institucional. Em outras palavras, ou pesquisa-se aquilo que a instituição deseja, ou então toda a responsabilidade de conseguir apoio e recursos passa a ser única e exclusivamente do pesquisador. Seria esse um dos preços a se pagar por 'sucesso' ou por apoio à pesquisa?

É um perigo cada vez mais concreto a (re)produção de uma 'ciência papagaio', calcada na mera repetição de uma série de referenciais famosos/prestigiosos/reconhecidos e, por isso, 'mais verdadeiros' que outros. Parecem cada vez mais raros estímulos para que as pessoas construam seus próprios objetivos de forma autônoma e inventem caminhos para chegar até eles.

[...] no âmbito de uma educação pastoral, não se pensa, de fato. [...] não se pensa singularmente, autonomamente, com seu próprio problema. [...] Deleuze (2006, p. 227-229) afirma a necessidade de "termos direito aos próprios problemas", uma vez que continuaremos escravos enquanto formos obrigados a 'pensar' problemas alheios (CARVALHO e GALLO, 2010, p. 296, grifo meu).

A maior parte dos caminhos parece apontar na direção do que Bourdieu (2006) chama de heteronomia na produção de ciência, uma vez que as pesquisas e as próprias subjetividades de investigadores e aspirantes a investigadores vêm sendo moldadas para que só se possa ter como objetivos e temas - e como caminhos para atingi-los - aqueles pré-estabelecidos e considerados válidos por outros.

Em um mundo como o contemporâneo, "o capitalismo 'lança modelos (subjetivos) do mesmo modo como a indústria automobilística lança uma nova linha de carros"” (LAZZARATO, 2014, p. 14). Somos estimulados a nos identificar quase de maneira hipnótica com as imagens de mundo veiculadas pela publicidade e pela cultura de massa (ROLNIK, 2006b, p. 5). E a academia lança modelos (subjetivos) de sucesso que nos seduzem.

Se formos pensar nos ideais contemporâneos de produtividade que balizam a maior parte das avaliações dos profissionais acadêmicos em universidades públicas brasileiras, seremos tentados a nos questionar se vale tudo para conseguir ser reconhecido pelas instituições e pelos outros acadêmicos como 'profissional de ponta'. Para ser reconhecido como um 'acadêmico de ponta' é preciso estar em programas de Pós-Graduação bem ranqueados pela CAPES, ter muitas publicações em periódicos bem avaliados pela CAPES,

\section{POLÊM!CA $\mid$ LABORE}


conseguir aprovação de projetos com financiamento de agências de fomento, ser professor visitante em universidades estrangeiras, entre outros. E o mais importante: não importam os meios utilizados para se chegar a esses fins nem como as relações que estabelecemos são conduzidas, ou ainda os valores (re)produzidos e estimulados. Só importam os resultados que atingimos dentro desses indicadores de 'qualidade' e 'reconhecimento'.

Parece fundamental o questionamento dessas ponderações para que não nos tornemos meros seguidores das 'religiões acadêmicas' tradicionais. Estamos aprisionados? Cláudio Moreira chega a comentar que se sente "armadilhado em um sistema Foucaultiano de poder que disciplina e pune cujo nome é Educação Superior” (DIVERSI e MOREIRA, 2009, p. 46).

Estamos fadados a criar apenas dentro dos 'cercadinhos do mercado'? Nesse sentido, Rolnik (2006a, p. 22) questiona: "como e onde se opera o estrangulamento vital que nos aprisiona no intolerável e nos asfixia?’. Maurizio Lazzarato afirma (2014, p. 20) que a mutação subjetiva "é fundamentalmente uma afirmação existencial e uma apreensão de si, dos outros e do mundo. E é sobre a base dessa cristalização não discursiva, existencial e afetiva que novas linguagens, novos discursos, novo conhecimento e uma nova política podem proliferar".

"Não adianta apenas escrever lindos textos super críticos e depois agir de maneira autocrática. Faça o que eu digo, mas não faça o que eu faço?”.

É, portanto, fundamental refletirmos a respeito dos padrões de sucesso que nos guiam dentro da Academia e quais ideais de sucesso nos guiam como acadêmicos. O que estamos dispostos a fazer para atingir esses ideais? E, neste sentido, também parece importantíssimo pensarmos a respeito de quais os ideais de sucesso e valores que nossas atitudes diárias ajudam a construir nas demais pessoas com as quais nos relacionamos na Academia.

Rolnik foi muito feliz quando discorreu a respeito da geopolítica da cafetinagem (2006b), pensada por ela como inicialmente ligada à questão artística. De acordo com seu texto, muitos dos protagonistas de movimentos das décadas anteriores caíram na armadilha de se deslumbrarem com o

entronamento de sua força de criação e de sua atitude transgressiva e experimental até então estigmatizadas e confinadas na marginalidade -, e fascinados com o prestígio de sua imagem na mídia e com os polpudos salários recém-conquistados, entregaram-se voluntariamente à sua cafetinagem. Muitos deles tornaram-se os próprios criadores e concretizadores do mundo fabricado para e pelo capitalismo nesta sua nova roupagem. Esta confusão decorre sem dúvida da política de desejo própria à cafetinagem das forças subjetivas e de criação. Um tipo de relação de

\section{POLÊM!CA | LABORÊ}

Polêmica - Revista Eletrônica da Uerj - Rua São Francisco Xavier, 524, $1^{\circ}$ andar bloco D, sl.1001 • Tels.: +55 21 2334-4088 / 4087 • http://www.e-publicacoes.uerj.br/index.php/polemica/index 
poder que se dá basicamente por meio do feitiço da sedução. O sedutor convoca no seduzido uma idealização que o sidera: este último identifica-se então com o agressor e a ele se submete, impulsionado por seu próprio desejo, na esperança de ser digno de pertencer a seu mundo (ROLNIK, 2006b, p. 6, grifos meus).

Ótimo conceito para o mundo acadêmico: cafetinagem acadêmica! É importante ressaltar que a cafetinagem guarda essa relação estreita em que a pessoa se entrega voluntariamente a(o) cafetã(o), inclusive (re)produzindo mundos e sentidos antes criticados. Os seduzidos se identificam e se submetem aos sedutores. Identificam-se com eles e com seus mundos, motivados por desejos de reconhecimento e de admissão a esses mundos que enxergam: querem ser admitidos ao mundo do sedutor!

Uma cafetinagem de forças subjetivas e de forças de criação de mundos, sentidos e subjetividades. Cafetinagem que opera pelo feitiço da sedução. Isso se coaduna com uma passagem de Ellis (2009, p. 64) em que ela comenta que sentiu "que tinha de aprender a pensar e conversar como outros acadêmicos se quisesse ser um membro pleno desta tribo [acadêmica]".

A educação configura-se, pois, como uma arena na qual forças conflitantes se digladiam; o condutor precisa 'dobrar a vontade' do conduzido, precisa amansá-lo, transformar a ave de rapina em animal doméstico, como afirmou o Nietzsche (1998, p. 33) de Genealogia da Moral. O conduzido, por sua vez, precisa deixar-se conduzir, ainda que resista em alguns momentos; precisa encontrar vantagens ou justificativas em deixar-se conduzir (CARVALHO, GALLO, 2010, p. 293, grifo meu).

Repito: enfrentamos um grande risco de sermos cafetinados? Quais os nossos ideais de sucesso dentro da Academia? Que mundos construímos diariamente por meio não apenas dos assuntos que tratamos, mas principalmente das relações que estabelecemos e de nossas atitudes? Em que medida já estamos cafetinados? Em que medida já oscilamos entre momentos e situações de agirmos como cafetões acadêmicos e outros de nos seduzirmos e sermos cafetinados?

- Também quero ser um professor famoso e reconhecido com bolsa de produtividade e dez artigos publicados por ano como o professor fulano!

- Dez por ano?? Então você vai copiar trechos de trabalhos de alunos ou repetir seus textos várias vezes em publicações diferentes? Ou vai dizer aos seus orientandos de mestrado e doutorado que tudo que eles escreverem enquanto estiverem sob sua orientação terá que ter o seu nome incluído como coautor?

\section{Considerações finais}

\section{POLÊM!CA $\mid$ LABORE}

Polêmica - Revista Eletrônica da Uerj - Rua São Francisco Xavier, 524, $1^{\circ}$ andar bloco D, sl.1001 • Tels.: +55 21 2334-4088 / 4087 • http://www.e-publicacoes.uerj.br/index.php/polemica/index 
A possibilidade da cafetinagem está sempre presente. Resta-nos lutar diariamente contra a possibilidade de tornarmo-nos cafetãs e cafetões acadêmicos, ou ainda cafetinados por outros cafetões e cafetãs. Admiro o pensamento de Larrosa (2015, p. 51) com relação ao que é um belo professor: "alguém que conduz alguém até si mesmo"; assim como aquele de alguém que aprende: "não alguém que se converte num sectário, mas alguém que, ao ler com o coração aberto, volta-se para si mesmo, encontra sua própria forma, sua maneira própria".

Pensando na Academia brasileira, como construir formas de sociabilidade, de sentir, pensar, trabalhar e desejar mais voltadas à vida, sem olhar criticamente para o que se faz, para o como se age e para o que se estimula com nossas atitudes e relações?

Lembro-me das palavras de Nietzsche (2008) quando ele afirma que tudo o que até agora chamamos de verdade, acaba sendo reconhecido como prejudicial, pérfida e subterrânea forma da mentira: “o pretexto sagrado de tornar 'melhor' a humanidade surge como a astúcia para esgotar a própria vida, para a tornar anémica. A moral como vampirismo" (p. 109). A moral vampírica da cafetinagem acadêmica.

Hoje, ao concluir este texto, lembro-me também de quando fui chamado por um colega de universidade de 'o cara da cafetinagem', por ter aprovado um projeto de pesquisa ligado à temática aqui desenvolvida. Não é à toa que Adams, Holman Jones e Ellis (2015, p. 65), escrevendo sobre o método autoetnográfico, dizem que "você se torna as estórias que você escreve".

\footnotetext{
o que modera e domestica é a virtude; assim fizeram do lobo um cão e do próprio homem o melhor animal doméstico do homem. "Nós colocamos a nossa caldeira mesmo no meio, - assim me confessa o seu sorriso - a igual distância dos gladiadores moribundos e dos imundos suínos". Isto, porém, é mediocridade, embora the chamem moderação (NIETZSCHE, 2013, localização 2654).
}

Por fim, é importante também apontar para a necessidade de realização de outras investigações dedicadas às relações acadêmicas e dos valores, modos de ver, sentir, trabalhar e viver nelas construídos.

Este texto não é apenas uma resposta à situação que vivi com relação ao episódio autoetnografado, mas um chamamento à atenção e reflexão por parte de todos nós a situações semelhantes que estudantes, professores e técnicos enfrentam em suas relações acadêmicas e, de alguma forma, se calam.

\section{POLÊM!CA $\mid$ LABORE}


Mas o que se fatigou é tão somente 'querido'; todas as ondas brincam com ele. E assim fazem todos os fracos: perdem-se no caminho. E o seu cansaço acaba por perguntar a si mesmo: "Porque seguimos este caminho? Tudo é igual!” É a eles que agrada ouvir pregar: "Nada vale a pena! Não deveis querer!” Mas isso, todavia, é um apelo ao servilismo (NIETZSCHE, 2013, localização 3231).

Apelo ao servilismo, à cafetinagem, ao conformismo. À identificação com imagens de sucesso daquilo que está posto. Façamos diferente!

\section{Referências}

ADAMS, Tony; HOLMAN JONES, Stacy; ELLIS, Carolyn. Autoethnography. New York: Oxford University Press, 2015.

BARROS, Roberto. Crítica científica e modelos interpretativos em Nietzsche. Trans/Form/Ação, v. 31, n. 2, p. 61-77. 2008.

BOURDIEU, Pierre. Homo Academicus. Paris: Minuit, 1984.

Os usos sociais da ciência: Por uma sociologia clínica do campo cientifico. São Paulo: Editora da UNESP, 2004.

Para uma sociologia da ciência. Lisboa: Setenta, 2006.

CARVALHO, Alexandre Fiordi de; GALLO, Silvio. Do sedentarismo ao nomadismo: intervenções para pensar e agir de outros modos na educação. Educação Temática Digital, v. 12, n. 1, p. 280-302, jul./dez. 2010.

CLARETO, Sônia Maria; OLIVEIRA, Marta Elaine de. Experiência e dobra teoria-prática: a questão da formação de professores. In: CLARETO, Sônia Maria; FERRARI, Anderson (Orgs.). Foucault, Deleuze e Educação. Juiz de Fora: Ed. UFJF, 2010. p. 65-89.

DELEUZE, Gilles. Conversações. São Paulo: Ed. 34, 1992.

Sobre o teatro: um manifesto de menos / O esgotado. Edição digital Kindle. Rio de Janeiro: Jorge Zahar Editor, 2012.

Nietzsche. Lisboa: Edições 70, 2013.

DIVERSI, Marcelo; MOREIRA, Claudio. Betweener talk: decolonizing knowledge production, pedagogy, and praxis. Walnut Creek: Left Coast Press, 2009.

ELLIS, Carolyn. Revision: autoethnographic reflections on life and work. Walnut Creek: Left Coast Press, 2009.

FERREIRA, José Maria Carvalho. Pedagogia libertária versus pedagogia autoritária. In: Vários. (Org.).

Educação Libertária. Rio de Janeiro: Achiamé/Movimento, 1996. p. 109-133.

FOUCAULT, Michel. O sujeito e o poder. In: DREYFUS, Hubert, RABINOW, P. Michel Foucault, uma trajetória filosófica: para além do estruturalismo e da hermenêutica. Rio de Janeiro: Forense Universitária, 1995. p. 231-249.

La creación de modos de vida. Estética, ética y hermenéutica. Barcelona: Paidós, 1999.

GARCIA, Maria Manuela Alves. O sujeito emancipado nas pedagogias críticas. Educação e Realidade, v. 26, n. 2, p. 31-50, jul./dez. 2001.

\section{POLÊM!CA $\mid$ LABORE}

Polêmica - Revista Eletrônica da Uerj - Rua São Francisco Xavier, 524, $1^{\circ}$ andar bloco D, sl.1001 • Tels.: +55 21 2334-4088 / 4087 • http://www.e-publicacoes.uerj.br/index.php/polemica/index http://www.labore.uerj.br • laboreuerj@yahoo.com.br 
Pedagogias críticas e subjetivação: uma perspectiva foucaultiana. Petrópolis: Vozes, 2002.

GUATTARI, Félix; ROLNIK, Suely. Micropolítica: cartografias do desejo. Petrópolis: Vozes, 2007.

LARROSA, Jorge. Pedagogia profana: danças, piruetas e mascaradas. 5. ed. Belo Horizonte: Autêntica Editora, 2015.

LATOUR, Bruno; WOOLGAR, Steve. The cicle of credibility. In: BARNES, Barry; EDGE, David (Ed.). Science in Context. Readings in the Sociology of Science. Milton Keynes/England: The Open Univ. Press, 1982. p. 35-43.

LAZZARATO, Maurizio. Signos, máquinas, subjetividades. São Paulo: Edições SESC São Paulo: n-1 edições, 2014.

NIETZSCHE, Friedrich. Ecce Homo. Como se chega a ser o que se é. Covilhã: LusoSofia press, 2008.

Assim falou Zaratustra. Kindle Edition. Textos para Reflexão, 2013.

RICHARDSON, Laurel. Fields of play: constructing an academic life. New Brunswick: Rutgers University Press, 1997.

ROLNIK, Suely. Cartografia sentimental: transformações contemporâneas do desejo. Porto Alegre: Sulina; Editora da UFRGS, 2006a.

Geopolítica da cafetinagem. Núcleo de Estudos da Subjetividade, 2006b. Disponível em:

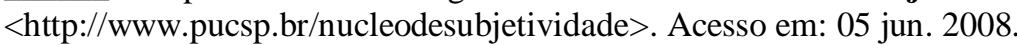

UBERTI, Luciane. Estudos pós-estruturalistas: entre aporias e contra-sensos? Educação e Realidade, v. 31, n. 2, p. 95-116, jul/dez. 2006.

VEIGA-NETO, Alfredo. Olhares. In: COSTA, Marisa Vorraber (Ed.). Caminhos investigativos: novos olhares em pesquisa em educação. Rio de Janeiro: DP\&A, 2002. p. 23-38.

VEIGA-NETO, Alfredo; LOPES, Maura Corcini. Há teoria e método em Michel Foucault? Implicações educacionais. In: CLARETO, Sônia Maria; FERRARI, Anderson (Orgs.). Foucault, Deleuze e Educação. Juiz de Fora: Ed. UFJF, 2010. p. 33-47.

VERSIANI, Daniela Beccaccia. Autoetnografias: conceitos alternativos em construção. Rio de Janeiro: 7Letras, 2005.

WEBER, Max. Sobre a universidade. São Paulo: Cortez, 1989.

Recebido em: 15/02/2016.

Aceito em: 19/07/2016.

\section{POLÊM!CA $\mid$ LABORE}

Polêmica - Revista Eletrônica da Uerj - Rua São Francisco Xavier, 524, $1^{\circ}$ andar

bloco D, sl.1001 • Tels.: +55 21 2334-4088 / 4087 • http://www.e-publicacoes.uerj.br/index.php/polemica/index 